\title{
The value of design patterns in designing teaching in online settings
}

\author{
Steven Warburton and Mark Perry \\ University of New England
}

\begin{abstract}
This paper presents an overview of the development of a pattern language for designing online learning and teaching. The aim of these patterns is to facilitate teachers in designing their online teaching environment using a scaffolded methodology that maintains and confirms their individual design agency. Design patterns capture expert knowledge in ways that can be reused to solve problems but never in the same way twice. Here, the authors provide an overview of the patterns, their interrelationship, and reflect on the value of design pattern and their use, highlighting how they can be deployed to enhance online teaching in an iterative design cycle approach.
\end{abstract}

KEYWORDS: online teaching; design patterns; pattern languages; Community of Inquiry; design cycle.

\section{Background on design patterns}

The design pattern approach provides a powerful way of bridging the gap between research and practice. Design patterns provide a meaningful way of capturing and then sharing knowledge in a particular domain of activity. At their core, they can be described as providing a solution to a problem in a context. As Alexander (1977) writes in his seminal volume on pattern languages:

Each pattern describes a problem which occurs over and over again in our environment, and then describes the core of the solution in such a way that you can use this solution a million times over, without ever doing it twice.

The intention behind Alexander's work was to offer a set of accessible conceptual resources relating to town planning and architecture that non-experts could use to shape their environment. The beauty of the principled approach he took was the way it balanced structure and rigour without sacrificing creativity. Alexander defined a design pattern as being constructed in three parts. First, the context, which asks under what conditions does a pattern hold and communicates the nature of both problem and solution. Second, the problem statement, which is often described as a system of forces, and outlines the tensions in the problem space that need to be resolved. And third, the solution, which indicates a design configuration that is capable of balancing the system of forces/tensions, in effect indicating a path that solves the problem being presented. Patterns are powerful design tools as they can be utilised by experts and non-experts in making rapid and grounded design decisions, even in relatively unfamiliar areas of practice. The notion of design patterns has been popular in the field of software engineering and as identified by Gamma et al. (1995) this conceptual understanding is reflective of how expert problem solvers design solutions in their everyday professions. Over the last three decades, design patterns have become visibly used in fields such as in educational design, web design, social action and many other areas (Schümmer, \& Lukosch, 2007; Mor et al., 2014; Public Sphere Project https://www.publicsphereproject.org)

\section{Introduction this pattern language}

There has been a steady and growing pressure for education providers to support flexibility for learners in space, time and place of study. Many institutions have responded by providing access to their learning and teaching using technologies, such as learning management systems and video conferencing which provide access to institutionally hosted virtual sessions in the form of tutorials and lectures.

There are now many solutions that offer platforms for robust and high quality video and audio that connect learners and teachers, but how do we ensure that these virtual spaces support effective and meaningful online teaching and learning? This paper presents a series of interconnected design patterns for planning, creating and delivering online face-to-face teaching sessions. These patterns touch not only on good pedagogical design but 
also on other critical considerations, such as virtual presence, the connectedness of learners and teachers, safety, confidence and the development of teaching place.

\section{Theoretical framework}

The theoretical framing of the patterns presented here is largely grounded in the Community of Inquiry framework (CoI). The CoI framework was first described by Garrison et al. (2000), and posited that creating a deep and meaningful educational experience requires the development of three interdependent elements that are identified as social, cognitive and teaching presence (Figure 1). These individual elements are further defined as:

1. Social presence (SP) is "the ability of participants to identify with the community (e.g., course of study), communicate purposefully in a trusting environment, and develop inter-personal relationships by way of projecting their individual personalities." (Garrison, 2009, p. 352)

2. Teaching Presence (TP) is the design, facilitation, and direction of cognitive and social processes for the purpose of realising personally meaningful and educationally worthwhile learning outcomes (Anderson, Rourke, Garrison, \& Archer, 2001).

3. Cognitive Presence (CP) is the extent to which learners are able to construct and confirm meaning through sustained reflection and discourse (Garrison, Anderson, \& Archer, 2001).

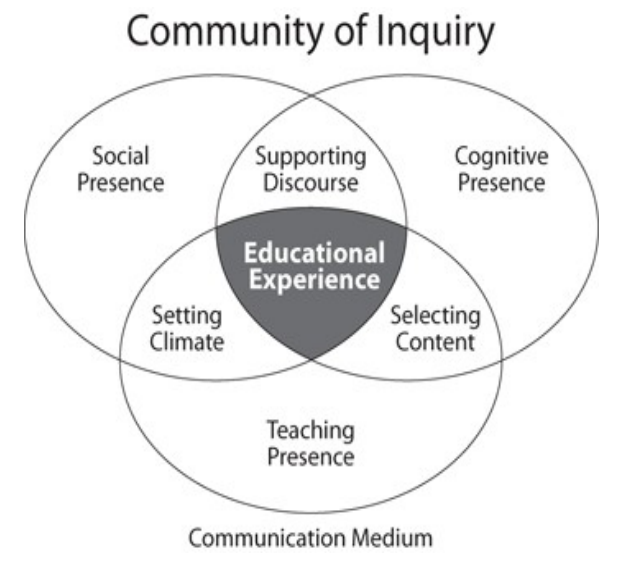

Figure 1: Community of Inquiry model highlighting the three key elements and including a description of the overlapping regions that comprise educational experience (Garrison et al., 2000)

\section{Methodology}

These patterns have been created through abstraction from relevant published practice orientated literature and drawn from the experience of the authors as academics working in higher education, through a combination of desk research and exploratory pattern mining sessions (for examples see Mor et al., 2014). Following refinement of the patterns into a standard structure and primary mapping to create a proto pattern language, these alpha state patterns are exposed to small group workshops to validate, refactor and finalise as beta or final release.

\section{Phase 1:}

Literature review: mining of practice-based research papers and reports in online learning and teaching, cross matching with theoretical works; exploration of grey literature;

Outcome: A first set of proto- or alpha state patterns.

\section{Phase 2:}

Workshop with expert practitioners; apply the 'rule of three' for validation;

Outcome: An iterated set of design patterns supported by a collection of real-life examples or case stories/studies. 


\section{Phase 3:}

Finalise the patterns by iterating (as needed) from alpha to beta to final form; refactor where necessary; check mapping and articulate links between patterns.

Outcome: Linked patterns that form a basic pattern language.

\section{Twelve Design Patterns for Designing Online Teaching and Learning}

In total twelve design patterns were generated for helping teachers in designing online teaching and learning. The twelve patterns were the product of three cycles of review by the authors (and external 'shepherd') that began with an initial crop of sixteen potential patterns. Each of the twelve patterns follows a standardised form consisting of eight clearly designated sections that add richness to the standard pattern form of problem, solution and context. Each pattern includes links to other patterns within the language to indicate how they can be used together in a coherent design effort. Due to space constraints, only one full design pattern is described below which is then followed by a summary table (Table 1) that provides a synopsis of each of the design patterns and the mapping of the primary design impact/s of the pattern in relation to the COI of model described above.

\section{Example pattern: [Environment Familiarisation Activity] - Pattern 1}

\section{Synopsis}

Ensure that learners familiarise themselves with the technical challenges and affordances that your online learning space presents.

\section{Context}

You are setting up an online teaching session with a new of group of learners who may or may not be familiar with the particular platform you have chosen. You want your first session to run smoothly and have followed the "Keep it Simple" rule.

\section{Problem}

There is always a first time using a new or unfamiliar technology. If students and instructors do not have the necessary basic technical skill-set they will not be able to participate actively in any learning and teaching activity, or event.

\section{Forces}

- There are a multitude of personalities, backgrounds and predispositions that an online teacher is confronted with, these can include: student resistance, background of learner (Millennials, Baby Boomers, digital immigrants, Gen X, Y, Z), anxiety, exaggerated expectations.

- Learners are individuals and each will have different levels of digital fluency based on previous experience and related competences. There may be a steep learning curve to develop the skills to operate in the technical environment.

- Learners typically struggle when faced with novel materials around subjects that they are not familiar with. This can be exacerbated by the introduction of digital technologies, such as virtual environments, the use of avatars, face-to-face (video) interactions with individuals at a distance - potentially on different continents.

\section{Solution}

Therefore, devise an activity with supporting notes that will help learners familiarise themselves with your chosen online platform. This training activity will ensure that all learners have the opportunity to learn baseline skills for access and participation. This may be an activity that can be completed individually in advance. Ensure that there is evidence of completion of the activity so that you can be assured all learners have acquired the necessary skills. [ASSESS ENGAGEMENT] to ensure understanding of how the systems work. It may be possible to direct your learners to training materials that already exist through the software vendors. Consider merging this with an [ICEBREAKER] activity.

\section{Watch out for}

Do not stereotype your learners and consider devising more than one activity to ensure different participants can find an appealing yet suitably challenging first engagement with your learning platform. 
Rationale

The technological setting should not get in the way of learning and teaching. It should be supporting the educational experience through enhancing social, cognitive and teacher presence (Garrision \& Anderson, 2003).

Examples:

- Microsoft offer introductory learning materials for their product suite. For example, see the Teams training video at https://www.youtube.com/watch?v=SMZuHDpINfo

- Conceptboard is a useful online whiteboard tool that provides a number of easily accessible tutorials on YouTube, for example, https://youtu.be/1R6phMDiGHA

Table 1: Summary table of design patterns and the zone of the CoI model where the pattern has most design impact ( $\mathrm{SP}$ - social presence; $\mathrm{TP}$ - teaching presence; $\mathrm{CP}$ - cognitive presence)

\begin{tabular}{|c|c|c|c|}
\hline ID & Design Pattern & Synopsis / Context & $\begin{array}{c}\text { CoI } \\
\text { Zone }\end{array}$ \\
\hline 01 & $\begin{array}{l}\text { ENVIRONMENT } \\
\text { FAMILIARISATION } \\
\text { ACTIVITY }\end{array}$ & $\begin{array}{l}\text { There is always a first time using a new or unfamiliar technology. If students } \\
\text { and instructors do not have the necessary basic technical skill-set they will not } \\
\text { be able to participate actively in any learning and teaching activity, or event. } \\
\text { Links to [03 ICEBREAKER] }\end{array}$ & SP \\
\hline 02 & STRONG PRESENCE & $\begin{array}{l}\text { Strengthen the effectiveness of virtual learning and teaching sessions by } \\
\text { facilitating the creation of a strong virtual presence for all participants in the } \\
\text { online space. }\end{array}$ & $\mathrm{TP}$ \\
\hline 03 & ICEBREAKER & $\begin{array}{l}\text { Break down the initial social barriers to participation by introducing a simple } \\
\text { task and report activity that allows all participants to engage with each in the } \\
\text { same social space. }\end{array}$ & $\mathrm{SP}$ \\
\hline 04 & SOCIAL CLIMATE & $\begin{array}{l}\text { Create a bounded space for social interaction that allows for participants to } \\
\text { meaningfully co-create a respectful and productive environment for learning. } \\
\text { Requires [02 STRONG PRESENCE] }\end{array}$ & SP \\
\hline 05 & SAFE SPACE & $\begin{array}{l}\text { All learners must feel safe in their learning setting. Unless they feel safe, they } \\
\text { cannot fully participate in the sharing and testing of ideas with each other and } \\
\text { the teacher. }\end{array}$ & SP \\
\hline 06 & $\begin{array}{l}\text { LEARNING } \\
\text { OUTCOMES }\end{array}$ & $\begin{array}{l}\text { Set clear and measurable learning outcomes to help students organise their } \\
\text { study and to ensure that you as a teacher have captured all of the elements } \\
\text { that you need to teach and then assess. }\end{array}$ & $\mathrm{CP}, \mathrm{TP}$ \\
\hline 07 & \begin{tabular}{|l} 
SHARED \\
EXPECTATIONS
\end{tabular} & $\begin{array}{l}\text { Build a sympathetic and shared understanding of the ground rules for } \\
\text { interaction that promotes mutual care for the learning space. } \\
\text { Uses [03 ICEBREAKER] and [04 SOCIAL CLIMATE]. }\end{array}$ & SP \\
\hline 08 & PERFECT GROUP SIZE & $\begin{array}{l}\text { Adjust your pedagogy to meet the group size. You have chosen a particular } \\
\text { platform for your teaching but you may not always be in a position to } \\
\text { determine the group size for your online teaching sessions (see Lohman \& } \\
\text { Finkelstein, 2000). }\end{array}$ & $\mathrm{TP}$ \\
\hline
\end{tabular}




\begin{tabular}{|l|l|l|c|}
\hline 09 & $\begin{array}{l}\text { PREPARATION } \\
\text { VERSUS } \\
\text { IMPROVISATION }\end{array}$ & $\begin{array}{l}\text { Avoid stilted and inflexible teaching sessions by balancing lesson preparation } \\
\text { with the opportunity to improvise. There is often a pressure to over prepare } \\
\text { and script the full teaching session in advance to ensure all of the content is } \\
\text { covered, but leave space open for feedback and cues to assess the learning } \\
\text { journey in real time. }\end{array}$ & TP \\
\hline 10 & $\begin{array}{l}\text { QUESTION AND } \\
\text { ANSWER }\end{array}$ & $\begin{array}{l}\text { Learning is a social activity and can be supported by question and answer } \\
\text { protocols that encourage interaction between learners and teachers. In a large } \\
\text { class (10+) you want to ensure that your session is as interactive as possible } \\
\text { by inviting questions and ensuring an intelligent dialogue and flow of answers } \\
\text { that interrogate your material and help others understand the concepts } \\
\text { explaining. }\end{array}$ & TP, CP \\
\hline 11 & $\begin{array}{l}\text { ASSESS } \\
\text { ENGAGEMENT }\end{array}$ & $\begin{array}{l}\text { Use the facilities of the learning platform to provide data on engagement and } \\
\text { participation. Use this data to adjust your learning and teaching focus and } \\
\text { approach. }\end{array}$ & TP \\
\hline 12 & THIS IS FEEDBACK & $\begin{array}{l}\text { Flag when you are providing feedback so that your learners understand where } \\
\text { they are on their learning journey. They should recognise where and how they } \\
\text { will arrive at the next point on their learning trajectory, and where they need } \\
\text { to go next. }\end{array}$ & CP \\
\hline
\end{tabular}

\section{Discussion and Conclusion}

This series of patterns outline an approach to conceptualising, preparing and running a learning experience in a virtual setting. The focus of these patterns is to provide a set of design solutions for educators who are new to working in an online setting and are challenged with developing a meaningful and satisfying educational experience. As our learning environments become increasingly technologically enhanced, these patterns may also be helpful prompts for experienced educators facing design challenges for their online sessions. The use of the CoI framework provides a theoretical reference point and grounding for the pattern language and individual patterns draw on other relevant research, for example around social presence and online pedagogies (Lui et al., 2009; Loch \& Reushle, 2008; Gunawardena \& Zittle, 1997). The work here creates a starting point for further design activity in the domain of online learning and teaching design using design patterns. We suggest the use of a meta design pattern or approach based on a simple design cycle (Figure 2) to scaffold the design process and indicate where patterns can best be deployed.

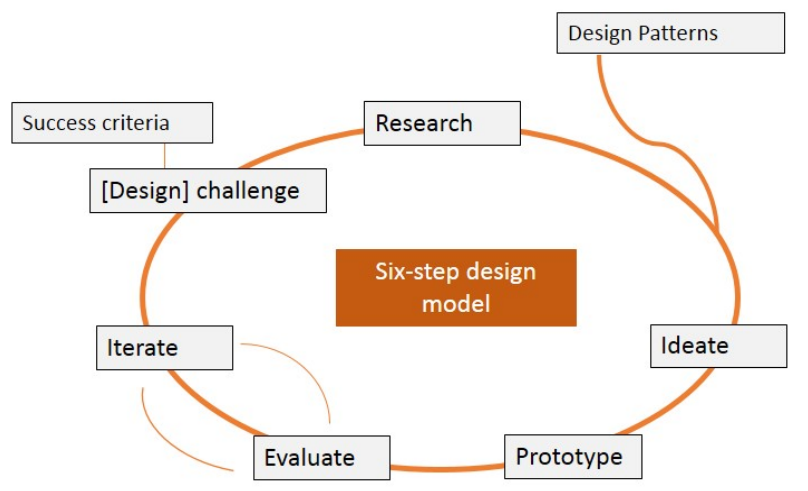

Figure 2: Iterative design cycle incorporating design patterns to scaffold ideation and solution. The design cycle starts with the design challenge and guides the learning designer through a series of scaffolded design actions (Warburton \& Mor, 2015).

The step between challenge to research can be cyclical. It highlights that that the initial design challenge may need to be questioned and the nature of the problem space will itself be altered by the design cycle. Through prototyping and evaluation stages new perspectives will have been gained that may suggest changes in direction and refinement of the design. The important role of the design patterns is to bring the expert voice into the design space to facilitate novice designers in the ideation of potential solutions. This create a hybrid space for 
design (Manzini \& Coad, 2015). Finally, as all design patterns remain open to iteration, the final loop (not indicated on the diagram here) allows for the results of the application of a designed solution to be fed back into the design pattern. This provides and adds to an evidential base for a particular design patterns, added under the 'Examples' section of the pattern form, that can help future designers with concrete examples of success.

\section{References}

Alexander, C., Ishikawa, S., Silverstein, M., Jacobson, M., Fiksdahl-King, I. \& Angel, S. (1977). A pattern language, towns, buildings, construction. Oxford University Press, New York.

Gamma, E., Helm, R., Johnson R., \& Vissides J. (1995). Design Patterns: Elements of reusable object-oriented software. Addison-Wesley.

Garrison, G. R., Anderson, T. \& Archer, W. (2000). Critical inquiry in a text-based environment: Computer conferencing in higher education. The Internet and Higher Education, 2(2), pp. 87-105.

Garrison, D. R. \& Anderson, T. (2003). E-Learning in the 21st century: A framework for research and practice. London: Routledge/Falmer.

Gunawardena, C. \& Zittle, F. (1997) Social presence as a predictor of satisfaction within a computer-mediated conferencing environment, American Journal of Distance Education, 11(3), pp. 8-26.

Loch, B. \& Reushle, S. (2008). The practice of web conferencing: where are we now? In: 25th Annual Conference of the Australasian Society for Computers in Learning in Tertiary Education (ASCILITE 2008): 30 Nov-3 Dec 2008, Melbourne, Australia.

Lohman, M.C. \& Finkelstein, M. (2000). Designing groups in problem-based learning to promote problemsolving skill and self-directedness. Instructional Science 28, 291-307. https://doi.org/10.1023/A:1003927228005

Lui, S., Gomez, J. \& Yen, C. J. (2009) Community College online course retention and final grade. Predictability of social presence. Journal of Interactive Learning, 8(2), 165-182.

Manzini, E., \& Coad, R. (2015). Design, When Everybody Designs: An Introduction to Design for Social Innovation. Cambridge, Massachusetts; London, England.

Mor, Y., Mellar, H., Warburton, S. \& Winters, N. Eds. (2014). Practical design patterns for teaching and learning with technology. Rotterdam, Netherlands: Sense.

Schümmer, T. \& Lukosch, S. (2007). Patterns for computer-mediated interaction. John Wiley \& Sons Ltd., Chichester, England.

Warburton, S. \& Mor, Y. (2015). Double Loop Design: Configuring Narratives, Patterns and Scenarios in the Design of Technology Enhanced Learning. In Y. Mor, M. Maina \& B. Craft (ed.), The Art and Science of Learning Design. Netherlands: Sense.

Warburton, S. \& Perry, M. (2020). The value of design patterns in designing teaching in online settings. In S. Gregory, S. Warburton, \& M. Parkes (Eds.), ASCILITE's First Virtual Conference. Proceedings ASCILITE 2020 in Armidale (pp. 106-111).

Note: All published papers are refereed, having undergone a double-blind peer-review process.

The author(s) assign a Creative Commons by attribution licence enabling others to distribute, remix, tweak, and build upon their work, even commercially, as long as credit is given to the author(s) for the original creation.

(C) Warburton, S. \& Perry, M. 2020 